\title{
BREVE PANORAMA DOS ESTUDOS DE LETRAMENTO(S) NO BRASIL - DOS ALFABETISMOS AOS MULTILETRAMENTOS
}

\section{BRIEF OVERVIEW OF LITERACY STUDIES IN BRAZIL - FROM LITERACY TO MULTILITERACY STUDIES}

\author{
Maria Cristina Macedo Alencar"
}

REsUmo: Apresentamos uma breve discussão sobre como se constituíram os estudos de letramentos no Brasil e refletimos quanto à questão da validade da utilização de tal conceito nos estudos da linguagem, tendo em vista as críticas formuladas aos estudos de letramento feitas por estudiosos de perspectiva freiriana de alfabetização. Assim, ao longo do texto trazemos as questões colocadas pelos Novos Estudos de Letramento, com a noção dos letramentos múltiplos e, pautamos ainda, o mais recente debate sobre a pedagogia dos multiletramentos (COPE; KALANTZIS, 2009; 2006). Não tivemos a pretensão de formular um texto completo e acabado sobre o tema, mas retomar algumas reflexões a fim de subsidiar os debates sobre alfabetização e ensino de língua materna pautados nas práticas sociais de uso da escrita.

Palavras-Chave: Letramentos. Multiletramentos. Revisão de literatura.

Aвstract: This article presents a brief discussion on how literacy studies were constituted in Brazil and a reflection on the validity of using this concept in language studies, considering educators' criticism based on Freire's studies to the use of the term literacy. Thus, throughout the text, issues raised by the New Literacy Studies with the notion of multiple literacies are discussed, and the most recent debate on the pedagogy of multiliteracies is highlighted (COPE; KALANTZIS, 2009; 2006). There is no intention to formulate a complete and finished text on the subject, but to return to some reflections in order to subsidize discussions on literacy and mother tongue teaching that are founded on the social practices on the use of writing.

KEYWORDs: Literacy. Multiliteracy. Literature review.

\footnotetext{
"Professora da área de Linguagem na Faculdade de Educação do Campo da Universidade Federal do Sul e Sudeste do Pará (UNIFESSPA) e doutoranda no Programa de Pós-Graduação em Linguística da Universidade Federal de Santa Catarina (UFSC).Email: cristinaufpa@yahoo.com.br
} 
Alfabetização, Alfabetismo E LETRAMENTOS

Os estudos sobre letramento, em certa medida, questionam uma dada concepção de alfabetização, a mais recorrente nos meios educacionais. Trata-se de uma alfabetização realizada no espaço escolar, cientificamente fundamentada, responsável pela promoção e aquisição individual simultânea da leitura e da escrita, entendidas essas como habilidades específicas que fornecem ao indivíduo instrumentos para se adaptar às necessidades sociais imediatas. Entretanto, esta não é a única concepção de alfabetização à qual o termo letramento tem sido contraposto, no decorrer dos últimos 20 anos no Brasil.

Apesar de os estudos de letramento já se terem consolidado como uma forte área de pesquisa nos campos da linguagem e educação no Brasil, entre os estudantes de graduação e muitos educadores que atuam há algum tempo no âmbito das séries iniciais e alfabetização, ainda são recorrentes questionamentos acerca do que se entende por alfabetização e por letramento. Também são comuns entre esses sujeitos questionamentos sobre a validade dos estudos de letramentos e em que se distinguem esses estudos das propostas teórico-metodológicas de alfabetização já conhecidas.

Com vistas a contribuir para o esclarecimento dessas questões realizamos o estudo ora apresentado. Nosso objetivo é apresentar, a partir da análise de extensa bibliografia sobre a constituição dos estudos de letramento no Brasil - influenciado pelos estudos dessa área no contexto anglófono como esse campo de pesquisa se difere dos estudos clássicos de alfabetização. Ao utilizarmos uma metodologia de análise comparativa da bibliografia disponível sobre os estudos de letramento procuramos sugerir um percurso histórico de constituição desta área no Brasil e demonstrar, aos educadores em formação inicial ou continuada, que os campos de estudo de letramento e alfabetização distanciam-se, principalmente, pela compreensão da linguagem como prática social. Ressaltamos, contudo, como se verá ao longo do texto, que apenas a perspectiva de alfabetização defendida por Paulo Freire em suas diversas obras já sinalizavam para o fato de que o processo de alfabetização precisa se dar pelas práticas sociais de uso da escrita.

Kleiman (1995) chamou atenção para o fato de que as críticas que os estudiosos do letramento fazem à alfabetização referem-se, especificamente, ao sentido desta que se popularizou entre os educadores-alfabetizadores, eximindo das críticas "os sentidos que Paulo Freire atribui à alfabetização, que a vê como capaz de levar o analfabeto a organizar reflexivamente seu pensamento, desenvolver a consciência crítica, introduzi-lo num processo real de democratização da cultura e de libertação" (KLEIMAN, 1995, p. 16). Contudo, alerta a autora que tal perspectiva restringiu-se aos meios acadêmicos e não atingiu amplamente as práticas dos alfabetizadores.

Em texto de 2007, Bartlett também destaca que a obra de Paulo Freire demonstra como os usos e significados da escrita estão estreitamente relacionados às estruturas e relações de poder que oprimem os mais pobres e que o domínio da escrita por eles também pode libertá-los: 
Finalmente, a percepção de que as práticas de alfabetização moldam e são moldadas por estruturas de poder deve muito à insistência de Paulo Freire de que, apesar da ausência e presença de letramento ter geralmente servido para oprimir os pobres, ler e escrever "a palavra e o mundo" também pode contribuir para a sua libertação (BARTLETT, 2007, p. 1619)

Também Barton (2000) e Gee (2008) têm nas obras de Paulo Freire a referência para os estudos que desenvolvem. Barton (2000) ressalta que o debate que faz sobre a autorreflexão crítica como a base da educação emancipatória de adultos foi inspirado no trabalho de Paulo Freire, a partir de seu conceito de conscientização. E Gee (2008) se pauta nas obras de Paulo Freire para mostrar como este contribui para os estudos de letramento emancipatório. Gee (2008) argumenta que nenhum teórico está mais associado ao letramento emancipatório que Freire, já que, para este, o aprendizado da leitura e escrita deve possibilitar às pessoas questionarem a realidade em que vivem.

De fato, em sua clássica obra $A$ importância do ato de ler, Freire argumenta a favor de uma:

Compreensão crítica do ato de ler, que não se esgota na decodificação pura da palavra escrita ou da linguagem escrita, mas que se antecipa e se alonga na

1 Tradução minha de "Finally, the realization that literacy practices shape and are shaped by larger power tructures owes much to Paulo Freire's insistence that, although both the absence and presence of literacy have generally served to oppress the poor, reading and writing "the word and the world" might also contribute to their liberation (1970, 1987)". inteligência do mundo. A leitura do mundo precede a leitura da palavra, daí que a posterior leitura desta não possa prescindir da continuidade da leitura daquele. Linguagem e realidade se prendem dinamicamente. A compreensão do texto a ser alcançada por sua leitura crítica implica a percepção das relações entre o texto e o contexto. (FREIRE, 2003, p. 9)

Paulo Freire já ressaltava a importância da reflexão sobre as práticas de linguagem não legitimadas pela escola e os usos e sentidos que a escrita tem para os sujeitos adultos não alfabetizados. Dessa maneira é possível admitir que os estudos de letramento e a concepção freiriana de alfabetização não se excluem, ao contrário, o conceito de "alfabetização crítica” cunhado por Freire está muito próximo do debate sobre "letramentos", particularmente, "os letramentos críticos" "que tratam os textos/enunciados como materialidades de discursos, carregados de apreciações e valores, que buscam efeitos de sentido e ecos e ressonâncias ideológicas" (ROJO, 2009, p. 114).

Ao longo do texto demonstraremos que, consideradas as distinções entre os processos de letramento e alfabetização, o que os educadores-alfabetizadores precisam ter clareza é de que a dissociação entre esses processos se constitui em um equívoco, uma vez que a entrada dos sujeitos no mundo da escrita deve ocorrer simultaneamente em contextos de práticas sociais de leitura e escrita, bem como por meio da aprendizagem das relações fonema-grafema, isto é, do sistema convencional de escrita (Cf. SOARES, 2005). 
LETRAMENTO: A CONSTRUÇÃO DE UM CONCEITO

Introduzido nas discussões acadêmicas no Brasil a partir da década de 80 , o termo letramento, apesar de já recorrente em muitas publicações no Brasil, ainda é novo entre os educadores e alfabetizadores. Segundo Kleiman (1995) e Soares (2005a) a palavra letramento foi introduzida em textos acadêmicos sob a influência do inglês literacy, que, durante a década de 90 , era traduzido por alfabetismo (cf. SOARES, 2005), designando algo mais do que até então se podia designar com a palavra alfabetização, "numa tentativa de separar os estudos sobre o impacto social da escrita dos estudos sobre a alfabetização, cujas conotações escolares destacam as conotações individuais no uso e na prática da escrita" (KLEIMAN, 1995, p. 16, ênfase da autora).

Em Soares (2005a) encontramos uma extensa reflexão sobre a introdução deste novo conceito nas discussões acadêmicas. O termo aparece pela primeira vez na obra No mundo da escrita, de Mary Kato (1986, p. 7). Nesta obra, "letramento" ainda não tem o sentido que adquiriu a partir dos trabalhos de Kleiman (1995). Em Kato (1986) "letramento" tem um sentido mais próximo de "alfabetismo", posto que a autora reflita sobre habilidades individuais de leitura para além da decodificação.

É possível admitir que a introdução de "letramento" no texto de Kato é apenas uma tradução de literacy, que, em inglês, àquele período e ainda hoje em alguns dicionários, é usado para se referir a três fenômenos distintos alfabetização, alfabetismo, e letramento. Não se percebe, nesta obra, a conotação e os sentidos que hoje se discutem de "letramento" relacionados a práticas sociais, a questões ideológicas e de poder imbricadas no uso, acesso e sentidos da escrita nas sociedades escriturárias ou sua introdução em sociedades de tradição oral, como se passa a discutir a partir da divulgação dos trabalhos de Street (1984).

Posterior ao trabalho de Kato (1986), "letramento" aparece na obra de Tfouni (2006[1988]). Na introdução desta obra, Tfouni distingue "alfabetização" de "letramento", afirmando que "talvez seja esse o momento em que 'letramento' ganha estatuto de termo técnico no léxico dos campos da educação e da Ciência Linguística" (TFOUNI, 2006[1988]), p. 07).

Para Soares (2005a), o uso de "letramento" como tradução da palavra inglesa literacy revela uma nova realidade social, isto é, uma nova palavra é criada em função de uma nova demanda social, pois, no Brasil, era muito comum tratar-se da realidade dos sujeitos que não dominavam as habilidades de leitura e escrita, ou seja, do analfabetismo, porém pouco se falava do "estado ou condição de quem responde adequadamente às intensas demandas sociais pelo uso amplo e diferenciado da leitura e da escrita" (SOARES, 2005a, p. 20).

Diante da realidade dos sujeitos alfabetizados que não conseguem fazer uso da leitura e escrita ${ }^{2}$ em práticas sociais letradas (letramentos), emerge a necessidade deste novo termo, que possibilita a reflexão sobre os processos históricos de expansão dos usos da escrita, observando "a emergência

${ }^{2}$ Isto é o que Rojo (2009) caracteriza como alfabetismos. 
da escola, o aparecimento das burocracias letradas como grupos de poder nas cidades, enfim, as mudanças políticas sociais, econômicas e cognitivas relacionadas com o uso extensivo da escrita nas sociedades tecnológicas" (KLEIMAN, 1995, p. 16). A definição e uso de um novo termo para discutir e investigar as questões de escrita e leitura em um dado grupo social justifica-se pela abrangência do termo "letramento" que não se limita a refletir sobre a "mera aquisição da 'tecnologia' do ler e do escrever, englobando as questões de uso competente e frequente da leitura e da escrita" (SOARES, 2005a, p. 23).

Soares (2005a), portanto, já indicia a ocorrência de níveis de letramento ${ }^{3}$ distintos, considerando que as sociedades do ocidente contemporâneo são sociedades caracterizadas pelos "letramentos", de modo que os sujeitos estão inseridos em grupos e situações sociais marcadas pelo uso cada vez mais amplo da linguagem escrita em diferentes esferas da sociedade. Nesses diferentes contextos de uso da escrita, os sujeitos, em função de suas experiências culturais e habilidades no uso da escrita, também a significam e dão sentido a suas práticas de maneiras distintas.

Soares (2005a) também ressalta não ser possível se falar em sujeitos mais ou menos letrados, haja vista não haver critérios, parâmetros de medição confiáveis. Desse modo, opta por tratar essas diferenças como "graus de letramento", posto que os sujeitos inserem-se cotidianamente em diferentes

\footnotetext{
${ }^{3}$ Conforme discutido no item 2.1 o que Soares está denominando "letramento", "níveis de letramento" e "graus de letramento" correspondem ao que Rojo (2009) denomina níveis de "alfabetismo".
}

situações, práticas sociais que lhes exigem maior ou menor grau de domínio das tecnologias de escrita.

Os sujeitos estão, portanto, inseridos num continumm de práticas de leitura, que vai desde a leitura de signos simples em notícias, num jornal popular, por exemplo, até a leitura de um livro inteiro ou teses científicas, sinalizando para a fragilidade de uma definição única para "letramento", que seria inadequada, visto que simplificaria a questão. Desse modo, Soares conclui

que o letramento é uma variável contínua e não discreta ou dicotômica; refere-se a uma multiplicidade de habilidades de leitura e de escrita, que devem ser aplicadas a uma ampla variedade de materiais de leitura e escrita; compreende diferentes práticas que dependem da natureza, estrutura e aspirações de determinada sociedade. (SOARES, 2005a, p. 112).

Note-se que a reflexão feita por Soares (2005; 2005a) está mais relacionada à discussão sobre os "alfabetismos" e sua investigação, que aos estudos de "letramento", de fato, como bem demonstrou Rojo (2009). Daí a importância de compreender as diferenças entre estes fenômenos.

Como se percebe o conceito de letramento no Brasil é construído historicamente, isto é, à medida que surgiam novos desafios nos processos de alfabetização o termo adquiriu uma conotação diferente. Assim podemos ilustrar essa variação nos sentidos do conceito com o quadro a seguir, a partir da discussão das autoras mais representativas deste tema: 
Tabela o1 - Significados do termo "letramento" na literatura da área

\begin{tabular}{l|l|l}
\hline PERÍODO & AUTOR E OBRA DE REFERÊNCIA & SENTIDOS DE LETRAMENTO \\
$\mathbf{1 9 8 5}$ & $\begin{array}{l}\text { Magda Soares artigo “As muitas } \\
\text { facetas da alfabetização", publicado } \\
\text { em periódico. }\end{array}$ & $\begin{array}{l}\text { Não usa o termo "letramento", mas faz uma } \\
\text { reflexão sobre o caráter individual e social da } \\
\text { alfabetização. Numa revisãodesteartigo publicada } \\
\text { em Soares (2005), relaciona a perspectiva social } \\
\text { da alfabetização ao que se passou a denominar } \\
\text { "letramento". A autora construiu em sua obra uma } \\
\text { abordagem curricular das práticas de linguagem } \\
\text { com foco nos alfabetismos. }\end{array}$ \\
\hline $\mathbf{1 9 9 5}$ & $\begin{array}{l}\text { Mary Kato-No mundo da escrita } \\
\text { O termo "letramento" é usado pela primeira vez } \\
\text { como um neologismo e um sentido mais próximo } \\
\text { de "alfabetismo". }\end{array}$ \\
\hline letramento Kleiman - Os significados do & $\begin{array}{l}\text { Influenciada pelos NSL contribui para a } \\
\text { compreensão dos "letramentos" como prática } \\
\text { social. }\end{array}$ \\
\hline
\end{tabular}

Contraposto aos estudos de letramento desenvolvidos nas décadas de 70 e 80 , nos Estados Unidos e Europa, nos quais se tentava associá-lo ao desenvolvimento intelectual e econômico das sociedades em que havia a escrita, Street (1984) destaca que o letramento tem significados políticos e ideológicos e por isso não pode ser considerado um fenômeno "autônomo", isto é, uma habilidade ou tecnologia de aquisição individual que provocaria o progresso, a civilização, a mobilidade social. Entendido este termo - "autônomo" como a noção de que "a escrita seria um produto completo em si mesmo, que não estaria preso ao contexto de sua produção para ser interpretado" (KLEIMAN, 1995, p. 22). Para Street (2003, p. 77), "autônomo" também se refere "à imposição de concepções ocidentais de letramento para outras culturas" ${ }^{4} \mathrm{ou}$, dentro de um mesmo país, a imposição de

${ }^{4}$ Tradução minha de: "[...] imposing western conceptions of literacy on to other cultures". letramentos de uma classe ou grupo social sobre outros.

Na perspectiva "ideológica", que podemos chamar de sociocultural, entende-se que as implicações e efeitos do letramento são amplamente determinados pelos hábitos e crenças de um dado grupo social. A reflexão é feita em função das diferentes práticas de letramento, determinadas social e culturalmente, a fim de compreender os significados específicos da escrita em cada situação e em cada grupo social. Segundo Street (2003), o modelo ideológico, portanto, oferece uma perspectiva de estudo sensível à compreensão da diversidade de práticas de letramento em função das diferenças culturais e dos contextos em que se realizam.

Este modelo postula que o letramento é uma prática social, não simplesmente uma habilidade técnica e neutra; que é sempre socialmente construído pautado por princípios epistemológicos. 
Trata-se de conhecimento: as formas pelas quais as pessoas se referem à leitura e escrita, sendo elas próprias enraizadas em concepções de conhecimento, identidade, e de ser [...]. Letramento, nesse sentido, é sempre contestado, tanto seus significados quanto suas práticas, são versões particulares, por isso é sempre "ideológico”. Elas estão sempre enraizadas em uma determinada visão de mundo e em um desejo de que uma dada visão de letramento domine e marginalize outras (STREET, 2003, p. 77-78) .

Esta perspectiva também é encontrada nos trabalhos de Barton e Hamilton (1998) e Barton (2000). Para esses autores, "como toda atividade humana, o letramento é essencialmente social e está localizado na interação entre as pessoas" (BARTON; HAMILTON, 1998, p. 3). Os autores argumentam que os "letramentos" são práticas sociais constituídas de eventos mediados por textos escritos. De acordo com Bartlett (2003), "os eventos de letramento, ou atividades que incluem o letramento, são práticas sociais produzidas por pessoas em situações específicas, com graus variados de poder e

\footnotetext{
${ }^{5}$ Tradução minha de: "This model posits instead that literacy is a social practice, not simply a technical and neutral skill; that it is always embedded in socially constructed epistemological principles. It is about knowledge: the ways in which people address reading and writing are themselves rooted in conceptions of knowledge, identity, and being. [...] Literacy, in this sense, is always contested, both its meanings and its practices, hence particular versions of it are always "ideological", they are always rooted in a particular world-view and in a desire for that view of literacy to dominate and to marginalize others".

${ }^{6}$ Tradução minha de: "Like all human activity, literacy is essentially social, and it is located in the interaction between people".
}

autoridade e, portanto, diferentes capacidades de influenciar o comportamento em tais eventos" (BARTLETT, 2003, p. 69)7. Nesse sentido, Barton e Hamilton (1998) afirmam que esses "letramentos" regulados por instituições sociais e relações de poder, se tornam mais dominantes, visíveis e influentes que outros.

Ao se admitir "letramento" como "um conjunto de práticas sociais que usam a escrita, enquanto sistema simbólico e enquanto tecnologia, em contextos específicos, para objetivos específicos" (KLEIMAN, 1995, p. 19), evidencia-se como as práticas escolares, responsáveis pela classificação dos sujeitos em alfabetizados e não alfabetizados, são apenas um tipo de prática, ainda que dominante, que desenvolve apenas algumas habilidades, determinando uma forma, dentre outras, de utilizar o conhecimento sobre a escrita. Mesmo diante de tal constatação, ainda é comum que a alfabetização e a escolarização, em nossa sociedade, sejam reconhecidas como fatores determinantes das diferenças nos modos de funcionamento letrado dos sujeitos.

É sobre essa questão que se pauta a crítica de Street (1984), uma vez que, para ele, tomar a escrita como parâmetro classificatório de diferenças essenciais entre pessoas ou grupos é algo arbitrário do ponto de vista teórico, além de revelar uma perspectiva etnocêntrica, na medida em que se ignoram “as relações sociais concretas, os conflitos de

\footnotetext{
${ }^{7}$ Tradução minha de "literacy events, or activities that include literacy, are social acts produced by people in specific situations with varying degrees of power and authority, and thus varying abilities to influence the conduct of such events".
} 
ordem política que determinam usos específicos da escrita em diferentes sociedades ou em diferentes grupos dentro de uma mesma sociedade" (RIBEIRO, 1999, p. 31).

A escola, principal "agência de letramento" em nossa sociedade, desenvolve atividades de ensino-aprendizagem da escrita como se a aquisição desta se constituísse num processo neutro, independentemente de considerações contextuais e sociais. Constantemente, a escola tem promovido "as atividades necessárias para desenvolver no aluno, em última instância, como objetivo final do processo, a capacidade de interpretar e escrever textos abstratos, dos gêneros expositivo e argumentativo, dos quais o protótipo seria o texto tipo ensaio" (KLEIMAN, 1995, p. 44). Aos sujeitos que não alcançam as habilidades previstas pela escola é imputada a responsabilidade pelo fracasso escolar.

Neste sentido, é possível afirmar que a escola tem se preocupado apenas com a "alfabetização" e os "alfabetismos", a partir de práticas de letramento específicas, voltadas para o processo de aquisição de códigos e, posteriormente, para algumas habilidades de leitura e escrita, geralmente focadas em competências individuais e não com os letramentos enquanto práticas sociais de uso da leitura e escrita. Afirmamos isso a partir da compreensão de que a escola ainda não tem conseguido trabalhar com o cotidiano dos alunos. Reconhecemos ser necessário pensar as práticas de letramento da esfera escolar também como práticas socioculturais e que

O termo "letramento escolar" não deveria a priori ser utilizado como algo necessariamente negativo ou perverso, autônomo e estático por natureza, mas como um conjunto de práticas discursivas da esfera escolar que envolvem os usos da escrita em contínua inter-relação com outras linguagens. (BUNZEN, 2010, p. 100)

Entretanto, vale lembrar que Barton e Hamilton (1998), já chamavam atenção para o fato de que as práticas privilegiadas na escola são relacionadas às práticas ditadas pelos grupos dominantes, isto é, são práticas institucionalizadas e que constituem os "letramentos dominantes". De acordo com a definição desses autores, os "letramentos dominantes" são práticas reguladas por organizações formais como escola, religião, o direito e local de trabalho. Por serem reguladas por essas instituições, são mais formalizadas, padronizadas e, por isso mesmo, gozam de alto valor na sociedade. "Em letramentos dominantes há peritos e professores que controlam o acesso ao conhecimento" (BARTON; HAMILTON, 1998, p. 252) .

Barton e Hamilton (1998) ressaltam que as pessoas vivenciam experiências com a escrita antes mesmo de adentrarem o espaço escolar, contudo estas experiências não são valorizadas neste contexto. A essas práticas de letramento originadas no cotidiano, fora dos contextos institucionalizados, os autores denominam "letramentos vernaculares", que consistem em práticas não reguladas por instituições sociais e nas quais não há um perito ou uma pessoa que controle o acesso aos conhecimentos.

\footnotetext{
${ }^{8}$ Tradução minha de "In dominant literacies there are experts and teachers through whom access to knowledge is controlled".
} 
As práticas de letramento vernacular são aprendidas informalmente. Elas têm suas raízes nas casas das pessoas e na sua educação. Uma importante distinção entre a aprendizagem vernacular e a aprendizagem que ocorre no contexto escolar ou de formação, é que aquela é "a aprendizagem não sistematizada por uma autoridade externa”. (BARTON; HAMILTON, 1998, p. $251-252)^{9}$

Entendem-se, assim, por "práticas de letramento" as formas culturais de uso da linguagem escrita - por isso constituídas de valores e sentimentos - que as pessoas desenvolvem, isto é, "práticas de letramento são o que as pessoas fazem com o letramento" (BARTON; HAMILTON, 1998, p. 6) ${ }^{10}$. Desse modo, investigar as práticas de letramento requer uma compreensão dos discursos sobre o letramento, uma reflexão sobre como os sujeitos significam a escrita e os letramentos, haja vista que

as práticas são processos sociais que ligam as pessoas umas com as outras, e que incluem cognições compartilhadas representadas em ideologias e identidades sociais. Práticas são moldadas por regras sociais que regulam o uso e a distribuição de textos, prescrevendo quem pode produzir e ter acesso a eles. Elas estabelecem a distinção entre os

\footnotetext{
9 Tradução minha de " [...] vernacular literacy practices are learned informally. They have their roots in people's homes and in their upbringing. An important distinction between vernacular learning and other learning, such as that within an educational or training context, is that vernacular learning is learning not systematised by an outside authority'.

${ }^{10}$ Tradução minha de "practices are what people do with literacy".
}

mundos individual e social, e são mais facilmente compreendidas nas relações interpessoais, dentro dos grupos e comunidades, e não como um conjunto de propriedades que residem nos indivíduos. (BARTON; HAMILTON, 1998, p. 7$)^{11}$

Relacionado à reflexão sobre as práticas de letramento está o conceito de "eventos de letramento". Segundo Barton (2000, p. 8), "eventos de letramento" "são episódios observáveis que surgem das práticas e são moldados por elas"12. Este é um conceito que ressalta a relação intrínseca entre os "letramentos" e o contexto social, bem como o fato de os "letramentos" serem sempre situados.

Barton e Hamilton (1998) demonstram que durante muitos anos os estudos de letramento discutiram dados que refletem, principalmente, sobre os "letramentos vernaculares", nos quais se deve pautar o processo de educação escolar. Segundo estes autores, a educação escolar deveria partir da reflexão acerca das "práticas de letramento" vivenciadas cotidianamente pelos aprendizes para daí possibilitar-lhes o acesso e a reflexão sobre os "letramentos dominantes", sempre num processo de leitura crítica.

\footnotetext{
${ }^{11}$ Tradução minha de "practices are the social processes which connect people with one another, and they include shared cognitions represented in ideologies and social identities. Practices are shaped by social rules which regulate the use and distribution of texts, prescribing who may produce and have access to them. They straddle the distinction between individual and social worlds, and literacy practices are more usefully understood as existing in the relations between people, within groups and communities, rather than as a set of properties residing in individuals".

${ }^{12}$ Tradução minha de "Events are observable episodes which arise from practices and are shaped by them".
} 
Esta perspectiva de ensino já havia sido apresentada e desenvolvida anos antes no Brasil, a partir dos trabalhos de Paulo Freire, nos projetos de alfabetização de adultos onde atuou. Paulo Freire mostrou que, para a alfabetização ser significativa para os aprendizes, o ensino de leitura e escrita deveria ser construído "a partir de palavras e de temas significativos à experiência comum dos alfabetizandos e não de palavras e de temas apenas ligados à experiência do educador" (FREIRE, 2003, p. 14). Freire sempre lutou pela realização de uma "alfabetização crítica” (cf. FREIRE, 1981 e 2003), na qual se deve considerar que

o aprendizado da leitura e da escrita não pode ser feito como algo paralelo ou quase paralelo à realidade concreta dos alfabetizandos. [...] Mais que escrever e ler que a "asa é da ave", os alfabetizandos necessitam perceber a necessidade de um outro aprendizado: o de "escrever" a sua vida, o de "ler" a sua realidade, o que não será possível se não tomam a história nas mãos para, fazendo-a, por ela serem feitos e refeitos (FREIRE, 1981, p. 13).

Os novos ESTUdos DE LETRAMENTO, os LETRAMENTOS MÚltiplos E OS MULTILETRAMENTOS

Mais recentemente nos estudos de letramento, tem-se ressaltado que não se pode mais tratar de letramento, no singular, mas dos letramentos: as muitas práticas sociais de usos e significações da escrita em diferentes contextos. Neste sentido, já há publicações tratando dos letramentos múltiplos (OLIVEIRA;
KLEIMAN, 2008; ROJO, 2009) e dos multiletramentos (ROJO, 2010).

Os Novos Estudos de Letramento (NEL/ NLS), principalmente a partir dos trabalhos de Street (1984) e de Barton e Hamilton (1998), têm argumentado que os letramentos são práticas sociais e por isso mesmo envolvidos em relações de poder e constituídos de valores e sentidos culturais mais amplos. Segundo Rojo (2009) são principalmente as noções de "práticas e eventos de letramento" que contribuem para esta discussão no reconhecimento de "letramentos dominantes" e de "letramentos vernaculares".

Os letramentos são construtos culturais, por isso mesmo seus significados variam ao longo do tempo e de acordo com os lugares em que as práticas de letramento se realizam. Nos NEL/NLS as investigações inicialmente tiveram foco nos "letramentos vernaculares", na investigação de "práticas de letramento" menos valorizadas e deslegitimadas socialmente. Atualmente, os estudos têm sido orientados também para uma reflexão sobre os "letramentos dominantes", tendo em vista os modos de acesso e significação destes no contexto escolar.

Bartlett (2003) também argumenta a favor de uma compreensão e investigação dos "letramentos múltiplos" e acrescenta a este debate a reflexão sobre o papel da linguagem na produção de estruturas de poder. Para tanto, faz uso de conceitos como capital, mercado e habitus linguísticos desenvolvidos pelo sociólogo francês Pierre Bourdieu.

Segundo a autora, com o conceito de "capital linguístico", Bourdieu demonstra a autoridade que pode ser atribuída a alguns 
falantes. Assim, "aqueles que detêm alto capital linguístico falam com o 'comando', ou seja, têm o poder de influenciar um ouvinte para a interpretação desejada"13 (BARTLETT, 2003, p. 68).

Os enunciados produzidos por esses falantes estão sempre inseridos num determinado "mercado linguístico" e regidos por um certo habitus linguístico. Este habitus consiste na "inclinação para a internalização de determinados tipos ou estilos de produção linguística, que são consideravelmente moldados por uma história pessoal de interação social e o sentido, valor da própria língua"14 (BARTLETT, 2003, p. 69). p.68).

Para Bartlett (2003), com esses conceitos, Bourdieu auxilia a compreender as microrrelações sociais e políticas que procuram impossibilitar as mudanças sociais a partir do acesso à educação formal pelas camadas populares, pois a escola exige certos modos de letramento sempre em detrimento de outros. Bourdieu (2004) detalha isto ao tratar a língua como um bem simbólico, que se constitui num capital de apropriação limitada a uns poucos. De modo mais específico, a afirmação de Bourdieu refere-se à língua escrita que se constitui num "capital linguístico” bastante rentável e eficaz em nossa sociedade.

\footnotetext{
${ }^{13}$ Tradução minha de "Those with high linguistic capital speak with "command," i.e., the power to influence a listener toward the desired interpretation".

${ }^{14}$ Tradução minha de "Linguistic habitus signifies the internalized inclination toward certain types or styles of linguistic production, which is considerably shaped by one's personal history of social interaction and one's sense of the value of one's language"
}

Quando uma língua domina o mercado, é em relação a ela, tomada como norma, que se definem, ao mesmo tempo, os preços atribuídos às outras expressões e o valor das diferentes competências. A língua dos gramáticos é um artefato que, universalmente imposto pelas instâncias de coerção linguísticas, tem uma eficácia social na medida em que funciona como norma, através da qual se exerce a dominação dos grupos. Detendo os meios para impô-la como legítima, os grupos detêm ao mesmo tempo, o monopólio dos meios para dela se apropriarem. (BOURDIEU, 2004, p.166).

Assim, a relação "letramentos dominantes" $x$ "letramentos vernaculares" tem se dado de tal modo que a desvalorização destes implica a maior valorização daqueles, principalmente nas práticas e discursos escolares, que centram suas bases na reprodução dos "letramentos dominantes" e no domínio individual de leitura/escrita (alfabetismos). Os estudos do letramento têm demonstrado que há um saber escolar-institucional legitimado, pelo qual

a escola exerce um poder de "violência simbólica", isto é, de imposição, às classes dominadas, da cultura - aí incluída a linguagem - das classes dominantes, apresentadas como a cultura e a linguagem legítimas: a escola converte a cultura e a linguagem dos grupos dominantes em saber escolar legítimo e impõe esse saber aos grupos dominados (SOARES, 2005b, p.54).

A prática escolar, assim, pode produzir nos sujeitos representações de si como 
"deficientes linguísticos" (cf. SOARES, 2005b). Representando-se assim, o sujeito insere-se num ciclo de legitimação (naturalização) da exclusão, haja vista que tal sentimento acaba por se tornar "a expressão mais legítima da dependência e da vassalagem, pois implica na impossibilidade de excluir o que exclui, única maneira de excluir a exclusão" (BOURDIEU, 2004, p. 132.)

Trata-se de um discurso que incute nos sujeitos a ideia de competência individual, de modo que o sucesso ou o fracasso em relação ao domínio de habilidades de leitura e escrita é sempre individual, não entrando no cômputo as práticas socioculturais de leitura e escrita negadas historicamente a esses sujeitos em seus processos de letramento, juntamente com outras práticas políticas, econômicas e culturais. Esta perspectiva corrobora uma visão mítica e evolucionista da escrita, muito presente em discursos de campanhas de alfabetização em massa (MATENCIO, 1995), nas quais "assume-se que é a escrita, e em especial a escrita alfabética, que representa um avanço substancial numa perspectiva cultural e cognitiva" (GNERRE, 1998, p.42).

Àqueles a quem é negado o direito de aprender a ler e a escrever, resta apenas assumir a sua condição de "deficientes culturais" - para usar expressão de Soares (2005b) -, que precisam se "adaptar" às exigências da sociedade em que se inserem, caso contrário continuarão a ser "cegos", um problema de cada um e de cada uma que não se apropriou do saber escolar, das práticas de leitura e escrita ali transmitidas e ofertadas a todos.

Diante de realidades como esta, os NEL/NLS procuram "situar as práticas de letramento no contexto do poder e da ideologia, e não como uma habilidade neutra, técnica" (STREET, 2006, p. 465). É nesta perspectiva que Street (2006) e Rojo (2009) demonstram ser necessário refletir sobre as práticas de letramento, observando que há diferentes modos pelos quais os sujeitos e os diversos grupos sociais atribuem sentidos aos usos da escrita e às atividades de ler e escrever nos mais variados contextos sociais e nos diferentes momentos históricos. Por isso, não é possível mais nos referirmos a "letramento", no singular, mas a "letramentos", no plural, uma vez que se admitam os argumentos apresentados acima.

Ao focalizar os usos e significados do letramento em diferentes culturas e contextos sociais as pesquisas com base no modelo "ideológico" de letramento reconhecem a multiplicidade de letramentos, uma vez que

o que veio a ser chamado de "Novos Estudos de Letramento" (NLS) (Gee, 1991; Street, 1996) representa uma nova tradição em considerar a natureza do letramento, focalizando não apenas a aquisição de habilidades, como em abordagens dominantes, mas o que significa pensar o letramento como uma prática social (Street, 1985). Isto implica o reconhecimento de letramentos múltiplos, variando de acordo com o tempo e espaço, mas também contestado nas relações de poder. NLS, então, não tomam nada como garantido no que diz respeito a letramentos e as práticas sociais com as quais se torna associado, problematizando o que conta como letramento em diferentes tempos e lugares e pergunta "que letramentos" são dominantes e quais são marginalizados ou 
resistentes. (STREET, 2003a, p. 77, ênfase adicionada. $)^{15}$

Segundo Street (2003; 2003a), a discussão central nos NEL/NLS tem sido o debate sobre as práticas de letramento locais em relação às práticas de letramento globais, ou o debate sobre o local/global. Na base desse debate estão as críticas acerca das pesquisas que investigam as práticas de letramentos locais, os letramentos vernaculares, não valorizados e deslegitimados socialmente. De acordo com o autor as principais críticas afirmam que o estudo das práticas de letramentos vernaculares não contribui para mudar a situação dos marginalizados, pois esses estudos focalizam práticas que as pessoas já realizam, o que não contribuiria para nenhuma mudança na situação dessas pessoas; ao contrário, as manteria sem o acesso às práticas legitimadas, sem condições de se integrarem às práticas exigidas pela sociedade cada vez mais globalizada. Seria, assim, mais uma forma de mantê-los excluídos.

Quanto a isso, Street (2003) argumenta que o estudo das práticas de letramentos locais permite compreender os modos de significação e usos da escrita por cada grupo social ou cultural. Assim, não contribui de modo

\footnotetext{
${ }^{15}$ Tradução minha de "What has come to be termed the "New Literacy Studies" (NLS) (Gee, 1991; Street, 1996) represents a new tradition in considering the nature of literacy, focusing not so much on acquisition of skills, as in dominant approaches, but rather on what it means to think of literacy as a social practice (Street, 1985). This entails the recognition of multiple literacies, varying according to time and space, but also contested in relations of power. NLS, then, takes nothing for granted with respect to literacy and the social practices with which it becomes associated, problematizing what counts as literacy at any time and place and asking "whose literacies" are dominant and whose are marginalized or resistant".
}

algum para a exclusão dos sujeitos, ao contrário, é o modo mais coerente de se construir programas de educação pública, buscando primeiro conhecer que valores e sentidos o grupo a ser escolarizado atribui aos letramentos dominantes e a suas próprias práticas de letramentos. Segundo o autor, só assim é possível propor, por exemplo, um programa coerente de alfabetização de adultos.

Street (2003) lembra que é possível que alguns acreditem que as práticas de letramentos dominantes, ao adentrar contextos locais, sejam assimiladas pelas pessoas de forma intacta. Mas, segundo ele, o que resulta do encontro entre o local e o global é sempre um híbrido. É sobre essas práticas de letramentos híbridas que se concentram os NEL/NLS, sem romantizar o local ou privilegiar o global, por exemplo, nas abordagens sobre a relação entre as práticas de letramentos locais e as da escola.

Disto se conclui que as práticas de letramentos sempre variam de um contexto e de uma cultura para outra, produzindo efeitos distintos em diferentes condições. Daí se considerar letramentos como práticas sociais, posto que as maneiras como as pessoas signifiquem sua relação com a escrita, as práticas de leitura e escrita, são pautadas por concepções de saber, de conhecimento e identidade, ou seja, estão sempre relacionadas a uma certa visão de mundo, de modo que uma dada visão pode marginalizar e dominar outras.

Diante disso, Rojo (2009) destaca que atualmente é o contexto escolar que desafia os estudiosos de letramento, pois aí se observa a convivência desses "letramentos 
múltiplos". Segundo a autora, no espaço escolar são realizadas práticas de letramentos "dominantes" e "vernaculares", legitimadas e não legitimadas socialmente, letramentos que estão "sempre em contato e em conflito, sendo alguns rejeitados ou ignorados e apagados e outros constantemente enfatizados" (ROJO, 2009, p. 106-107), o que demonstra a multiplicidade de letramentos que constituem o contexto escolar e outras esferas de produção de linguagem. A autora ressalta que:

o conceito de letramentos múltiplos é ainda um conceito complexo e muitas vezes ambíguo, pois envolve, além da questão da multissemiose ou multimodalidade das mídias digitais que lhe deu origem, pelo menos duas facetas: a multiplicidade de práticas que circulam em diferentes esferas da sociedade e a multiculturalidade, isto é, o fato de que diferentes culturas locais vivem essas práticas de maneira diferente (ROJO, 2009, p. 109).

Relacionado ao debate recente sobre os "letramentos múltiplos", Rojo (2010) acrescenta que há ainda a emergência do conceito de "multiletramentos", o qual foi articulado por um grupo de pesquisadores autodenominado New London Group (Grupo de Nova Londres - GNL), para os quais este prefixo multi-está relacionado tanto às multissemioses e diferentes linguagens envolvidas nos processos de significação dos textos multimodais contemporâneos, quanto aos diferentes contextos sociais e à pluralidade cultural dos sujeitos envolvidos nos processos de criação/significação (design) desses textos.
A proposta do GNL, apresentada em 1996 (cf. COPE; KALANTZIS, 2006, p. 05) como um manifesto programático de uma "pedagogia dos multiletramentos", trouxe duas grandes contribuições aos estudos de letramento a partir do conceito de "multiletramentos": os princípios da "multissemiose" e do "multiculturalismo" como base para o desenvolvimento de projetos de ensino e construção de novos currículos. O estudo daquela, segundo os autores, visa a que se leve em conta, na educação escolar, a leitura e escrita dos letramentos contemporâneos ou novos letramentos (hipertextos, videoclipes etc.) e a relação dos sujeitos com os textos do ambiente digital, a fim de que os aprendizes possam dominar as novas tecnologias de maneira crítica. Para tal ensino os autores enfatizam a necessidade de que os educadores construam uma metalinguagem adequa$\mathrm{da}$ às realidades dos alunos. O segundo elemento, o debate sobre "multiculturalismo", é a base para promover uma educação para a diferença, ou seja, uma educação em que as diferenças de cultura, linguagem e gênero, dentre outras, não sejam barreiras para o sucesso na escola e no cotidiano fora dela.

Vale ressaltar que esses teóricos antecipam uma realidade escolar que ainda começava a se manifestar timidamente, pois à época em que o GNL discutia a necessidade de se desenvolver um ensino pautado pela reflexão sobre a emergência de diferentes gêneros e textos nas novas mídias, a partir da ampliação do acesso ao meio digital, e exigência de diálogos interculturais e educação para a diferença, ainda se discutia a constituição da hoje Europa Unificada e as Novas 
Tecnologias de Informação (TICs) ainda não eram acessíveis a grande parte da população. De certa maneira, eles anteciparam o debate, hoje efervescente, das exigências de uma educação para o "multiculturalismo" e para a leitura crítica de textos "multimodais"/"m ultissemióticos” (COPE; KALANTZIS, 2009).

O manifesto do GNL enfatiza que o ensino deve se realizar por meio de projetos construídos a partir das diferenças multiculturais dos aprendizes. Isto é, para que seja efetivada a "pedagogia dos multiletramentos", o currículo deve ser construído a partir do mundo da vida dos alunos com projetos de ensino que promovam uma formação para o trabalho, a vida pessoal e a cidadania, a fim de que seja ampliado, de maneira crítica, o repertório dos aprendizes (COPE; KALANTZIS, 2006).

A proposta do NLG, centrada na educação para o trabalho, o civismo e a vida pessoal, é feita a partir do reconhecimento das múltiplas identidades que os sujeitos podem construir em diferentes situações da vida. Daí decorre a noção de "pluralismo cívico". Este traz a ideia de que os espaços públicos passam a ser lugares onde as diferenças são reconhecidas e negociadas. Com esta convivência entre os diferentes em locais públicos, os sujeitos se complementariam porque teriam a chance de ampliar seus repertórios culturais e linguísticos. Desconstrói-se a ideia de Estados-Nação que impõem línguas e culturas padrões; ao contrário, afirmam-se as diferenças, de maneira que a todos seja possível o acesso às riquezas, independentemente de marcadores de identidade. "Esta éa base para uma sociabilidade coesa, uma nova civilidade em que as diferenças são usadas como recurso produtivo e em que as diferenças são a norma”. (COPE; KALANTZIS, 2006, p. 15$)^{16}$.

Nesta educação para o "pluralismo cívico", desenvolvem o conceito de Projetos (Designs) de futuros sociais. A partir desta perspectiva, argumentam que a escola deve oferecer as ferramentas para que todos os alunos possam ter possibilidades iguais de "projetos de futuros sociais". Tal educação deve partir das experiências do aluno, numa perspectiva "multicultural" e "multimodal/multissemiótica”, para que construam significações (meaning making). A noção de designs reconhece que todas as pessoas aprendem certas convenções e modos de significar, mas, lembra que elas também constroem novas significações, isto é, são designers de sentido. Logo, todos também podem ser "designers de futuro social - os futuros locais de trabalho, os futuros do espaço público e futuros da

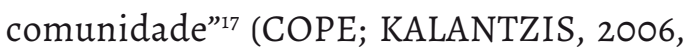
p. 7). Assim, afirmam:

Nosso interesse é discutir a proposição de que o currículo é um projeto de futuro social e debater a forma geral como o design complementa a pedagogia de letramentos na maneira indicada pela noção de multiletramentos. [...] Diferentes concepções de educação e de sociedade levam a formas muito

\footnotetext{
${ }^{16}$ Tradução minha de "This is the basis for a cohesive sociality, a new civility in which differences are used as a productive resource and in which differences are the norm".

${ }^{17}$ Tradução minha de "And, as designers of meaning, we are designers of social futures - workplace futures, public futures, and community futures".
} 
específicas de currículo e de pedagogia, que por sua vez incorporam projetos para futuros sociais. Para conseguir isso, precisamos nos engajar em um diálogo crítico com os conceitos fundamentais do capitalismo rápido, de formas pluralistas emergentes de cidadania e de modos de vida diferentes. Esta é a base para um novo contrato social, uma nova comunidade. (NLG, 2006, p. 19) ${ }^{18}$.

Certamente a principal contribuição do GNL foi terem chamado atenção para a necessidade de que os currículos escolares precisam ser construídos tendo em vista as múltiplas práticas de linguagem e formas de texto e cultura. Apresentam uma pedagogia instrumental com uma análise "meta" para o letramento crítico, ao destacarem que este deve ser desenvolvido a partir do mundo da vida/cultura local do aluno para a sala de aula. O desafio na "pedagogia dos multiletramentos" é, então, educar para que os sujeitos negociem suas identidades nos diferentes contextos ou mundos (da vida pública, privada e do trabalho) e assim possam construir projetos (designs) de futuro social.

É necessário, porém, questionar na proposta do GNL a maneira como apresentam, principalmente, a "educação para o trabalho".

\footnotetext{
${ }^{18}$ Tradução minha de "Our purpose is to discuss the proposition that curriculum is a design for social futures and to debate the overall shape of that design as we supplement literacy pedagogy in the ways indicated by the notion of multiliteracies. [...]Different conceptions of education and society lead to very specific forms of curriculum and pedagogy, which in turn embody designs for social futures. To achieve this, we need to engage in a critical dialogue with the core concepts of fast capitalism, of emerging pluralistic forms of citizenship, and of different lifeworlds. This is the basis for a new social contract, a new commonwealth".
}

Esta é apresentada numa perspectiva bastante vinculada ao modelo "neoliberal", visando atender exigências de um sistema que requer que os indivíduos se adequem às especificidades desse modelo econômico a fim serem inseridos no mercado de trabalho. A proposta do GNL, em certa medida, sugere currículos que se restringem a atender as exigências de formação de trabalhadores para as novas demandas da economia globalizada, que requer um profissional cada vez mais flexível e qualificado, apto a desenvolver múltiplas funções, sem destacar as implicações sociais e políticas das exigências desse modelo e sem refletir sobre a necessidade de formação crítica dos trabalhadores para que possam protagonizar uma possível transformação social. Falta ao debate desses autores uma proposta de resistência e superação das limitações impostas aos trabalhadores, como propunha Paulo Freire em todo o seu trabalho sobre a “alfabetização crítica” (FREIRE, 1981; 2003).

\section{CONSIDERAÇõES FINAIS}

Rojo (2009; 2010) reconhece a contribuição da "pedagogia dos multiletramentos" para o debate sobre a revisão, democratização e ampliação do acesso aos letramentos e textos que circulam na escola, particularmente os múltiplos letramentos da esfera digital, com enfoque não apenas sobre o que é valorizado socialmente, mas também sobre as práticas e letramentos do cotidiano dos alunos. Tal perspectiva argumenta a favor do ensino dos "letramentos críticos" na escola, pautada pela percepção de que os aprendizes precisam desenvolver uma compreensão crítica dos diversos textos e discursos que 
circulam nas variadas esferas sociais, assumindo uma atitude "responsiva-ativa" diante dos textos e discursos, pois

compreender a enunciação de outrem significa orientar-se em relação a ela, encontrar o seu lugar adequado no contexto correspondente. A cada palavra da enunciação que estamos em processo de compreender, fazemos corresponder uma série de palavras nossas, formando uma réplica. Quanto mais numerosas e substanciais forem, mais profunda e real é a nossa compreensão (BAKHTIN/VOLOCHÍNOV, 2004, p. 131-132).

Isto implica o reconhecimento do caráter enunciativo da linguagem, marcado por uma historicidade, ideologias, por características do contexto de produção dos textos orais ou escritos, pelas implicações deste contexto na organização dos discursos e que à escola cabe realizar um ensino de língua materna que explicite como as práticas de linguagem são constituídas de valores e são sempre intencionadas (ROJO, 2009, p.112).

Somente com a percepção destes aspectos será possível questionar a imposição de letramentos dominantes e a marginalização das práticas de linguagem de grupos sociais deslegitimados socialmente e, ao mesmo tempo, a necessidade de domínio desses mesmos letramentos dominantes a partir da reflexão das práticas de letramento vernaculares dos grupos de alunos.

Ainda vigora em nosso país um modelo tradicional de escola e de ensino de língua no qual são negligenciados os diferentes modos de relação com a escrita construídos por grupos sociais que não tiveram acesso ao letramento escolar, de maneira que são negligenciados os múltiplos letramentos que constituem o cotidiano das camadas populares de nossa sociedade. A partir da compreensão do que seja um ensino de língua materna pautado pelas práticas sociais de uso da língua escrita e seus significados para os diferentes grupos sociais, será possível trilhar caminhos por onde começar um processo de ensino/aprendizagem que seja afirmador de identidades positivas para crianças, jovens e adultos que reivindicam o saber agenciado pela escola.

\section{REFERÊNCIAS}

BAKHTIN, M. M.; VOLOCHÍNOV, V. N. Marxismo e Filosofia da Linguagem. São Paulo: Hucitec, 2004.

BARTLETT, L. Human Capital or Human Connections? The Cultural Meanings of Education in Brazil. Teachers College Record, Vol. 109, nº 7, July 2007, pp. 1613-1636.

. Social Studies of Literacy and Comparative Education: Intersections. Current Issues in Comparative Education, 5(2), 2003, pp. 67-76.

BARTON, D.; HAMILTON, M. Local literacies: reading and writing in one community. London: Routledge, 1998.

Literacy practices. In: BARTON, D.; HAMILTON, M. \& IVANIC, R. (Orgs.). Situated literacies. London: Routledge, 2000. pp.07-15. BOURDIEU, P. A economia das trocas linguísticas. São Paulo: Perspectiva, 2004. BUNZEN, C. Os significados do letramento escolar como uma prática social. In: VÓVIO, C.; SITO, L.; DE GRANDE, P. (org.). LetramentoS: 
rupturas, deslocamentos e repercussões de pesquisas em Linguística Aplicada. Campinas, SP: Mercado de Letras, 2010.

COPE, B.; KALANTZIS, M.. Multiliteracies: new literacies, new learning. Pedagogies: An International Journal, V. 4(3), 2009, p. 164-195.

Multiliteracies - Literacy Learning and the design of social futures. New York: Rutledge, 2006.

FREIRE, P. A importância do ato de ler: em três artigos que se completam. São Paulo: Autores Associados: Cortez, 2003.

Ação cultural para a liberdade. Rio de Janeiro: Paz e Terra, 1981.

GEE, J. P. Social linguistics and literacies: ideology in discourses (2nd ed.). London and Bristol, PA: Taylor and Francis, 2008, pp. 62-66. GNERRE, M. Linguagem, escrita e poder. São Paulo: Martins Fontes, 1998.

KATO, M. No mundo da escrita: Uma perspectiva psicolingüística. São Paulo: Ática, 1986.

KLEIMAN, A. B. (org.). Significados do Letramento: uma nova perspectiva sobre a prática social da escrita. Campinas-SP: Mercado de Letras, 1995.

MATENCIO, M. de L. M. Analfabetismo na mídia: conceitos e imagens sobre o letramento. In: KLEIMAN, A. B. (org.). Significados do Letramento: uma nova perspectiva sobre a prática social da escrita. Campinas-SP: Mercado de Letras, 1995, pp. 239-266.

NEW LONDON GROUP (GNL). A pedagogy of multiliteracies: designing social futures. In: COPE, B.; KALANTZIS, M. Multiliteracies - Literacy Learning and the design of social futures. New York: Routledge, 2006 [2000].

OLIVEIRA, M. do S.; KLEIMAN, A. (orgs.). Letramentos múltiplos: agentes, práticas, representações. Natal: EDUFRN, 2008.
RIBEIRO, Vera Masagão. Alfabetismo e atitudes. Campinas- SP: Papirus; São Paulo: Ação Educativa, 1999.

ROJO, R. H. R. Alfabetismo(s), letramento(s), multiletramento(s): desafios contemporâneos à Educação de Adultos. IN: COSTA, R. P.; CALHÁU, S. (orgs). “... e uma Educação pro povo, tem?". Rio de Janeiro: Editora Caetés, 2010. (Seminários NEAd, vl. 1)

Letramentos múltiplos, escola e inclusão social. São Paulo: Parábola Editorial, 2009.

SOARES, M. Alfabetização e Letramento. São Paulo: Contexto, 2005.

Letramento: um tema em três gêneros. Belo Horizonte: Autêntica, 2005a.

Linguagem e escola: uma perspectiva social. São Paulo: Ática, 2005b.

STREET, B. V. Perspectivas interculturais sobre letramento. Filologia lingüística portuguesa, São Paulo, n. 8, p. 465-488, 2006.

The Limits of the Local-'Autonomous' or 'Disembedding'? International Journal of Learning . Columbia Teachers College, Columbia university,Vol. 10, p. 2824-2830, 2003.

What's "new" in New Literacy Studies? Critical Approaches to Literacy in Theory and Practice. Current Issues in Comparative Education, Vol. 5(2), pp. 77-91. Columbia Teachers College, Columbia university, $2003 a$.

Literacy in theory and practice. Cambrigde: Cambrigde University Press, 1984. TFOUNI, L. V. Adultos não-alfabetizados em uma sociedade letrada. Edição revisada. São Paulo: Cortez, 2006 [1988].

Recebido para publicação em 01 out. 2015 Aceito para publicação em 20 março 2016. 